\title{
IGNACIO DE LAS CASAS, JESUITA Y MORISCO
}

\author{
Youssef El Alaoui*
}

La figura del Padre Ignacio de las Casas (1550-1608), uno de los pocos moriscos que fueron admitidos en la Compañía de Jesús, nos es poco conocida. Este morisco granadino, que había estudiado en la Casa de la Doctrina del Albaicín (Granada) entre 1562-1567, fue alumno de otro jesuita de origen morisco, muy conocido éste, el Padre Juan de Albotodo. Ingresó en la Compañía de Jesús en 1572 e hizo sus cuatro votos en 1603.

A través de los escritos de Ignacio de las Casas, último testimonio digno de interés de la Compañía de Jesús sobre la cuestión morisca, hemos realizado un estudio comparativo de la política de evangelización y de asimilación llevada a cabo con los moriscos y con los indios en el Reino de Quito y en la región de Maynas ${ }^{1}$. En este artículo nos limitaremos, por razones evidentes de espacio, a sintetizar algunos de los aspectos más interesantes de su obra.

\section{METODOLOGÍA MISIONAL DE IGNACIO DE LAS CASAS}

La obra de Ignacio de las Casas es, como lo subraya Francisco de Borja de Medina ${ }^{2}$, muy representativa de la mentalidad de la orden y es de gran interés para entender el papel desempeñado por los jesuitas en la política de evangelización y de asimilación de los moriscos.

* Universidad de Rouen, ERAC-CRIAR (Francia).

1. Jesuitas, moriscos e indios. Estudio comparativo de los métodos de evangelización de la Compañía de Jesús según los tratados de José de Acosta (1588) e Ignacio de las Casas (1605-1607), tesis doctoral bajo la dirección del profesor Alain Milhou, defendida en la Universidad de Rouen en 1998. Este trabajo se inscribe en la trayectoria de estudios (o de hipótesis de trabajo) comparatistas de autores tales como Robert Ricard (1931), Pierre Duviols (1971), Antonio Garrido Aranda (1980), Serge Gruzinski (1989), Bernard Vincent (1990) y, recientemente, M. ${ }^{a}$ Dolores Palomo Infante, Beatriz Suñé Blanco y Mercedes García-Arenal (1992).

2. Francisco de Borja MEDINA, de «La Compañía de Jesús y la minoría morisca», Archivum Historicum Societatis Iesu (ARSI), 57, n. ${ }^{\circ} 113,1988$, p. 5. 
Para realizar el estudio y edición crítica de sus memoriales, nos hemos basado en el manuscrito inédito de la British Library (ms. Add. 10238), volumen en cuarto de 261 folios.

Los escritos de las Casas fueron utilizados por Damián Fonseca en su Justa expulsión de los moriscos de España con la instrucción, apostasía y traición dellos (Roma, 1612); Pascual Boronat y Barrachina lo cita en Los moriscos españoles y su expulsión ${ }^{3}$ y nos lo presenta como un teólogo de mérito de la Compañía de Jesús. En fechas más recientes, Medina se ha interesado por el personaje en su extenso artículo sobre la actividad misionera jesuita con los moriscos en España desde la creación del colegio de Gandía (1545) hasta la expulsión de 1609-1614; ; el autor utiliza sobre todo el primero de los cuatro escritos de que se compone el manuscrito, la «Información acerca de los moriscos de España» dirigida al Papa Clemente VIII en 1605, aportando preciosos datos biográficos y bibliográficos. Aparte de estas obras, Ignacio de las Casas seguía siendo un ilustre desconocido para la mayoría de los investigadores de la cuestión morisca.

El manuscrito, cuyo título artificial es De los moriscos de España, es una compilación de cuatro memoriales:

1. «Información acerca de los moriscos de España dada a nuestro sanctíssimo padre, Papa Clemente VIII, por el Padre Ignacio de las Casas de la Compañía de Jesús este año de mil y seiscientos y cinco» (1605), fol. 1r a fol. 72v.

Está estructurado en tres partes:

Capítulos 1 a 5: historia de los moriscos, su situación y descripción de los métodos empleados por las autoridades.

Capítulos 6 a 7: análisis de los métodos propuestos por ciertos teólogos y expertos en la materia.

Capítulos 8 a 10: métodos propuestos por las Casas.

En anejos, las Casas utiliza una serie de documentos oficiales (instrucciones, memoriales) que nos dan una visión de conjunto de la política de asimilación llevada a cabo en el siglo XVI, fol. 73 a fol. 140.

3. Pascual Boronat y BARRACHINA, Los moriscos españoles y su expulsión, ed. facsímil, Granada, 1992 [1 $1^{\mathrm{a}} \mathrm{ed}$. 1901], tomo 2, p. 56, nota 30 .

4. Otros autores citan algunos aspectos de la trayectoria de este jesuita morisco: Ana LABARTA, «Notas sobre algunos traductores de árabe en la Inquisición valenciana (1556-1609)», Revista del Instituto Egipcio de Estudios Islámicos, 21, Madrid, 1981-1982, pp. 108-112; Ricardo GARCÍA CÁRCEL cita un pasaje de la Información en su artículo «L'Inquisicion de Valence», en Les Morisques et l'Inquisition, Paris, Publisud, 1990, p. 162; T.D. KENDRICK, Saint James in Spain, Londres, 1960; Darío CABANELAS, El morisco granadino Alonso del Castillo, Granada, 1965, pp. 241-294 y Miguel José HAGERTY, Los libros plúmbeos del Sacromonte, Madrid, ed. Nacional, 1980. 
2. «Memorial al Rey [Felipe III] en su supremo Consejo de Aragón».

En este memorial describe la política de la Corona con los moriscos de Granada y de Valencia y propone soluciones, fol. 141r a fol. 161r. Aporta también una serie de documentos (Junta de la Capilla Real de Granada de 1526, instrucciones reales al arzobispo Gaspar de Avalos en 1530 y resoluciones de la junta de Toledo de 1539).

3. «Al supremo Consejo de la sancta Inquisición».

Este memorial se compone de dos partes. La primera resume la situación de los moriscos, fols. 161v a 178r, y la segunda trata de los libros plúmbeos del Sacromonte y de la participación de las Casas en el descubrimiento de la superchería, fol. 178v a fol. 188r.

4. «Al Padre Christóbal de los Cobos, provincial de la Compañía de Jesús» (1607).

Junto con la «Información», éste es uno de los más interesantes y originales ya que en él las Casas expone sus ideas sobre el interés de utilizar el árabe como instrumento para la conversión de los moriscos.

El hilo conductor de estos cuatro memoriales es el mismo: crítica de los métodos empleados en la evangelización y asimilación de la minoría morisca y proposición de soluciones centradas sobre todo en el aprendizaje del árabe y la educación de los niños para utilizarlos como auxiliares de la evangelización, en un primer tiempo, y como actores de dicha evangelización tras una fase de formación que desembocaría en su aceptación en el seno de la Iglesia (clero regular o secular). Estos documentos nos aportan numerosos datos sobre diversos aspectos de la vida cotidiana de la minoría, sobre la mentalidad de la época y la actitud de la Compañía de Jesús.

Los acontecimientos referidos por las Casas coinciden con las etapas más destacadas de la historia de los cristianos nuevos de moros y le sirven de base para desarrollar su metodología.

El objetivo principal de nuestro jesuita era intentar explicar las razones por las que los moriscos no se habían convertido sinceramente a la religión católica y analizar las dificultades a las que todo el personal encargado de la evangelización se enfrentaba a la hora de buscar una solución conveniente que les llevara a "odiar y aborrecer la secta del perverso Mahoma". En esta perspectiva, las Casas justifica plenamente la ruptura de las Capitulaciones de Granada apoyándose en la tesis del historiador Martín de Viciana (1502-1582), para quien los mudéjares de Granada se habían convertido voluntariamente, y rechazando la de Jerónimo de Zurita (1512-1580) que opinaba lo contrario. Según las Casas, toda España estaba bajo el poder de un rey católi-

\footnotetext{
5. «Información...», fol. 2r.
} 
co y, como tal, éste no podía aceptar la permanencia en sus territorios de súbditos no católicos tal y como lo estipulaba el canon 3 del concilio de Toledo VI (638). Las Casas consideraba que el "intento de los sanctos reyes era el verlos convertidos porque entendían que los más dellos, o casi todos, eran descendientes de christianos assí de las donzellas que los reyes sus antecesores daban por parias a los moros como de infinitas otras mugeres tomadas por fuerça y de tantos millones de hombres y mugeres que, o por temor, o por otros intentos faltaron a la ley de su redemptor"6; el punto de vista que adopta aquí es el mismo que el del humanista Pedro de Valencia ${ }^{7}$ en lo que se refiere a la hispanidad de los moriscos. Ambos se apoyaron en esa hispanidad para justificar la adopción de medidas más clementes y de métodos más suaves. El proceso de recuperación de España se había acabado y había que recuperar a las "ovejas descarriadas". A partir de 1526, no quedaba, oficialmente, ningún musulmán en España; los moriscos hacían su entrada en la historia. Según su región de origen, se les llamaría convertidos y mudéjares en Castilla, tagarinos en Aragón y moriscos en Granada y Valencia. Como ya lo hemos apuntado, las Casas deseaba que se llegara a una conversión profunda de los mudéjares, pero lo que desaprobaba era el método empleado para hacerlo, causa, según él, de la falta de sinceridad de los moriscos porque se había llevado a cabo:

\footnotetext{
"sin preceder el cathecismo necessario y predicación evangélica en ninguna parte de España por no tener quien supiesse predicalles en su lengua natural arábiga ni entender ellos sufficientemente la española ni aún bastantemente para entender siquiera un razonamiento; la qual falta como tan grave y essencial a sido y es hasta oy la causa de todos los daños y del no convertirse de veras, pues, aviéndoles faltado como e dicho la doctrina, que forçosamente avía de anteceder a su baptismo según el mandato del redemptor y hecho el baptismo tan violento, tampoco an tenido jamás quien los instruyesse en lo que avían de guardar después de baptizados de suerte que fuessen capaces de lo que se les enseñava"8.
}

La homogeneización de la sociedad española proseguía su camino pero la ruptura entre las dos comunidades se había consumado. La situación de los moriscos no cesaba de empeorar; los abusos del clero, de los funcionarios y de los señores de vasallos eran tales que, según las Casas, "siendo mahometanos y estándose en su secta por estar en estos reynos de España, eran fielíssimos amigos de los christianos y súbditos a sus señores y reyes y a su costa guardavan las

6. «Información...», fol. 7r.

7. Pedro de VALENCIA, Tratado acerca de los moriscos (1606), copia del 5/12/1623, BNM ms. 8888, fols. $22 \mathrm{r}-22 \mathrm{v}$ : los moriscos "en quanto a la complexión natural, y por el consiguiente en quanto al ingenio, condición y brío son españoles como los demás que havitan en España pues ha casi novecientos años que nacen y se crían en ella”.

8. «Información...», fol. 10v. 
costas del mar de los corsarios de su secta e yvan a las guerras contra ellos; baptizados, [...] se convirtieron en crueles enemigos".

La población morisca formaba un grupo heterogéneo cuyo grado de aculturación era más o menos avanzado según la región de origen. Las Casas distinguía cuatro grupos:

1) Los de Castilla, cuyo grado de aculturación y de integración era el más elevado. Con un escaso conocimiento del árabe, se vestían "a la cristiana", podían llevar armas y ejercer diversos oficios; según las Casas, eran buenos cristianos. Lo único que los diferenciaba de la población cristianovieja era que vivían en morerías, no comían cerdo ni bebían vino y solían casarse sólo con miembros de su comunidad. Paradójicamente, esta asimilación de los moriscos castellanos planteaba serios problemas; los cristianos viejos desconfiaban de ellos "porque ni en habito ni en lengua se differencian" 10 .

2) Los de la Corona de Aragón. Éstos tampoco sabían árabe pero eran más indiscretos que los castellanos. Se les acusaba de practicar sus ceremonias religiosas en público, de tener contactos con África del Norte, en el caso de Valencia. La mayoría conocía sus oraciones en árabe pero sin entenderlas, según las Casas, "como nuestros viejos y viejas rezan en latín lo que ni entienden ni saben" ". Esto demostraría que las medidas represivas habían dado buenos resultados; el empobrecimiento intelectual de la mayoría de la población morisca era patente. Los alfaquíes, los que aún podían ejercer clandestinamente, intentaban, mal que bien, salvar la situación, pero su margen de maniobra era cada vez más reducido excepto en Valencia donde la resistencia de los moriscos a la ocupación de su espacio vital (cultural y cultual) era más fuerte.

3) Los de Valencia y Granada eran los menos aculturados y los que mantenían un vínculo más persistente con la civilización musulmana. Los primeros sabían hablar árabe y, según las Casas, la mayoría sabía leerlo y escribirlo pero no entendían el castellano ni el valenciano. Los de Granada eran, siempre según las Casas, mucho más dóciles y mejores cristianos por

que se habían convertido voluntariamente al catolicismo y vivían mezclados con la población cristianovieja desde su expulsión de Granada en 1570. La realidad era distinta ya que el hecho de haber estado más tiempo en contacto con el Islam los había endurecido y su dispersión en Castilla tuvo como consecuencia despertar el Islam latente de los moriscos castellanos como lo señala Bernard Vincent ${ }^{12}$.

9. Ibidem, fol. 13r.

10. Ibidem, fol. $17 \mathrm{v}$.

11. Memorial a Cristóbal de los Cabos, fol. 203r.

12. Bernard VINCENT, «Les Morisques, l'intolérance et l'économie», Revue de la BN, n 29, 1988, p. 26. 
Tenemos por lo tanto una especie de demarcación entre moriscos aculturados o en vías de aculturación (Castilla y Aragón) y moriscos impermeables (Granada y Valencia); pero en realidad, desde el levantamiento de las Alpujarras, ya no se hacía una distinción entre el "buen morisco" y el "morisco malo" sino que se juzgaba que su estado era "lastimosíssimo y miserabilíssimo assí por lo que dellos sienten y dizen los demás christianos como por lo que en esto pasa con verdad, [...] que son todos moros y más observantes de su secta que los que están aliende el mar libremente en ella"13. Las Casas consideraba que la conversión sincera de todos los moriscos de España dependía de la de los valencianos por ser, como lo fueron antes los de Granada, "avidos y tenidos por más nobles que todos los demás descendientes de moros en estas partes, y la segunda por tenellos por los más doctos en su secta como los tienen hasta oy doquiera que están y les dan en todo la prima" 14 .

El temor a la conspiración, a la alianza de los moriscos con los enemigos de España, tanto cristianos como musulmanes, hacía de ellos, ya fuesen castellanos, granadinos, aragoneses o valencianos, unos espías, unos quinta columnistas:

"porque entran a servir como hijos de christianos viejos en casas graves, saben los secretos más interiores, van no conocidos a las guerras y tienen officios en ellas, y siendo enemigos, se ven claros los daños por los quales, no prevenidos, se destruyen las repúblicas y se an destruido y asolado gravíssimas.

Aquí entra lo que se dize comúnmente que esta gente tiene el manejo de lo mejor de la república española, assí en lo que se tragina de una parte a otra como de lo que se vende en particular y en junto, que, si se considera, tiene infinitos cabos por los quales se descubren grandíssimos daños si se concede que son nuestros enemigos. El enriquezerse ellos y tener los nierbos [sic] de las guerras que son los dineros, el escondellos mientras no hallan su occasión o pasallos a las naciones enemigas con su comodidad y provecho y daño de España, el poder, quando quisiessen, juntarse en conciertos y avenenar las mercancías del sustento de la gente común y aún mayor; y porque no aya sucedido, no ay seguridad que no sucederá si los ánimos son contrarios" $" 15$.

Estos temores podían ser justificados en las zonas costeras por las frecuentes incursiones de los piratas berberiscos, pero podemos suponer que eran más bien el fruto de una obsesión colectiva alimentada por las tensiones internas e internacionales que una realidad ya que, en lo que se refiere a una posible colusión con los turcos, hay que subrayar que la potencia otomana se

13. «Información...», fol. 13v.

14. Ibidem, fol. 57r.

15. Memorial al Rey Felipe III, 145v. 
sirvió de ellos, abandonándolos a su propia suerte en aras de su expansión imperialista y dejando de lado la solidaridad religiosa ${ }^{16}$.

Aunque con el bautismo los moriscos se habían convertido oficialmente en cristianos, seguían siendo súbditos de segunda categoría y padecían discriminaciones de todo tipo. Las Casas nos dice que había sido "testigo de vista de muchos que se han querido favorecer de nosotros y de[s]pegarse de los suyos y sólo no han hallado favor sino maltrato y gran de [s] amparo" ${ }^{17}$.

Antes de exponer sus ideas, las Casas intenta analizar las causas del fracaso de la política de la Corona, la cual perseguía tres objetivos: convertirlos, hacerles olvidar sus ritos, costumbres y ceremonias religiosas y controlar sus movimientos para evitar posibles levantamientos o alianzas con el exterior.

En cuanto a la conversión, las Casas destaca los aspectos siguientes: predicación e instrucción en castellano, método coercitivo para obligarles a frecuentar las iglesias y asistir a los sacramentos, enterramientos en la iglesias e intervención de la Inquisición. Por otra parte, para erradicar cualquier huella de islamismo en España, la política de la Corona se hizo cada vez más represiva. Una serie de juntas y asambleas se encargaron de darle un marco legal a dicha política represiva hasta culminar en la publicación de la pragmática de 1567, que adoptó las medidas tomadas en el concilio provincial de Granada de 1565, el cual a su vez reactivó las medidas de la Junta de la Capilla Real de 1526. La apertura, la negociación, la tolerancia dieron paso al enfrentamiento de posturas religiosas intransigentes. El morisco ya no podría hablar de excepción cultural, de particularismo regional como lo hiciera, en un memorial elevado en 1566 a la Audiencia de Granada en vísperas de la publicación de la pragmática de 1567, el notable morisco Francisco Núñez Muley, quien se hacía eco de la desesperación de su pueblo formulando una patética pregunta: “¿de qué sirve querer perderse tales memorias ansí en los ábitos o traxes como en los sobrenombres [...]?"18.

16. Francisco MÁRQUEZ VillanUEVA, «El problema historiográfico de los moriscos», Bulletin Hispanique, 86, $\mathrm{n}^{\mathrm{o}}$ 1-2, 1984, p. 101; cf. Antonio DOMÍNGUEZ ORTIZ y Bernard VINCENT Historia de los moriscos. Vida y tragedia de una minoría, Madrid, Alianza Editorial, 1989, pp. 58-63.

17. «Información...», fol. 16r.

18. Bernard VINCENT, «Estudio preliminar» a la reedición de Los moriscos del Reino de Granada según el sínodo de Guadix de 1554, Granada, Archivum, 1996, pp. XXXV-LII. Núñez Mulev, el principal abogado de la nación morisca según Bernard Vincent, pretendía convencer a las autoridades de la posibilidad de cohabitar bajo el mismo techo, la España cristiana, con costumbres diferentes; sus argumentos sobre la defensa y valorización de la lengua árabe, sobre la posibilidad de ser cristianos y diferentes del resto de la masa cristianovieja, sobre el respeto de los particularismos influenciaron la obra de las Casas y su defensa de una nación árabe y cristiana tan cara al arzobispo de Granada, Fray Fernando de Talavera, aunque el punto de vista de Muley fuese, a nuestro parecer, más político. Cf. Ma Jesús RUBIERA MATA, «La familia morisca de los Muley-Fez, príncipes meriníes e infantes de Granada», Sharq al-Andalus, 13, 1996, pp. 159-167. 
Para Ignacio de las Casas la adopción de todo este arsenal represivo era improcedente para este tipo de población que no estaba dispuesta a recibir el mensaje cristiano; al contrario, no hacía más que irritarla y acentuaba su resentimiento hacia la sociedad cristianovieja porque según él:

\footnotetext{
“¿de qué provecho a sido, ni es, el predicarles en lengua que ni entienden ni quieren entender? o ¿qué utilidad se a sacado de hazellos por fuerça decorar el texto de la doctrina que tienen por falsa? [...] y ¿qué utilidad se puede sacar del forçarlos a acudir a los divinos mysterios a los que los tienen por meras idolatrías y están allí cometiendo diabólicos sacrilegios? y ¿qué sacrílega confessión hará el que la tiene por burla? ¿Quién jamás vio, para convencer los ánimos, no sólo hablalles en lengua tan bárbara para ellos como la suya para nosotros y tan obscura e inintelligible, sino aún prohibilles bien la suya materna tan amada naturalmente como la propia madre, que por eso tiene tal apellido de materna?"19.
}

Los moriscos gozaban por lo tanto de circunstancias atenuantes; su comportamiento se explicaba por el hecho de que no entendían lo que se les quería imponer. Por ello, no podían ser castigados por los errores cometidos contra la fe porque no se les había instruido como era debido. Consciente de la dificultad de la tarea, las Casas propone una serie de soluciones que girarían en torno a las ideas siguientes: respeto de los moriscos, mejor formación del personal encargado de la evangelización, aprendizaje del árabe, lucha contra los dogmatizadores o alfaquíes y sobre todo, educación y formación cristiana de los niños y jóvenes moriscos.

\section{SUPRESIÓN DE LAS DESIGUALDADES ENTRE MORISCOS Y CRISTIANOS VIEJOS}

Tras el bautismo de los mudéjares de la Corona de Aragón, en 1525, el rey les había prometido "las libertades y franquezas que como christianos [...] se os deven guardar $y$ hazeros todo favor y buen tratamiento como a fieles súbditos nuestros" ${ }^{20}$, y unos años antes, en las Capitulaciones de Granada, "que los moros no darán ni pagarán a sus altezas más tributo que aquello que acostumbran a dar a los reyes moros" ${ }^{21}$. La realidad era otra; los moriscos pagaban más impuestos que los cristianos viejos, casi el doble más ${ }^{22}$. Las numerosas quejas

19. «Información...», fols. 22v-23r.

20. Ibidem, fols. $7 \mathrm{v}-8 \mathrm{r}$.

21. Mercedes GarcíA-Arenal, Los moriscos, Madrid, Biblioteca de Visionarios, 1975, p. 24.

22. Como lo subraya Serafín Tapia, "la fiscalidad discriminatoria era no sólo un mecanismo de exacción económica sino también una forma de represión y de demostración de dominio político", en «Los moriscos de Castilla la Vieja, ¿una identidad en proceso de disolución?», 
elevadas a las autoridades eran letra muerta ya que había muchos intereses en juego para la Corona, la Iglesia y los señores de moriscos que se aprovechaban de ese ambiente de arbitrariedad. Todo ello contribuía a acentuar el rechazo por parte de la minoría morisca de la sociedad cristiana de la que se sentían excluidos, y favorecía un repliegue que les conducía a buscar en su comunidad, en sus raíces, en la cultura de sus antepasados, el consuelo, la comprensión, el reconocimiento que un amplio sector de la sociedad les denegaba ${ }^{23}$. No obstante, existía una corriente que, aunque aborrecía la religión musulmana, era favorable a una integración de los moriscos con medios más humanos y rechazaba las exacciones y abusos de que eran víctimas. Las Casas, que formaba parte de esa corriente en la que encontramos figuras como las del noble valenciano Jerónimo Corella, el franciscano Antonio Sobrino, el arbitrista Pedro de Valencia entre otros, proponía primero atraerlos con buenas obras, como lo recomendaban las Escrituras, y sobre todo preconizaba la desaparición de las desigualdades con la supresión de la discriminación fiscal, "reduziéndolo todo a lo que pechan y pagan los demás christianos y no pidiéndoles otros particulares tributos por ser los que son" ${ }^{24}$. Nuestro jesuita se oponía también a las concordias (pactos o acuerdos financieros) entre la Inquisición y las aljamas porque consideraba que era una de las causas por las que la conversión de los moriscos no era sincera porque éstos pensaban que "qualesquier errores o trayciones contra su Dios o rey se rescatan con dineros" ${ }^{25}$; además estas concordias podían ser peligrosas ya que con el pretexto de reunirse para recaudar el dinero acordado, podían tramar una conspiración. Para atraerlos, había que hacerlo con amor, caridad y ejemplaridad, castigando "ásperamente a los que les dicen palabras injuriosas como sois muy usadas, perros moros, moriscos, mudéjares o convertidos y esto conviene sumamente al bien destas almas y paz de España"26.

Sharq al-Andalus, 12, 1995, p. 188; ver también Carmen BARCELÓ, «Formación de la minoría musulmana: los inicios del largo camino hacia el destierro», Historia de Castellón. Castellón: Levante de Castellón, tomo 1, 1992, p. 194.

23. Sector que Janer llama "el partido intolerante" en la introducción de su Condición social de los moriscos de España, Barcelona, Alta Fulla, ed. facsímil, 1987, p. 52. Según Rafael Carrasco, si los moriscos rechazaron la asimilación no fue porque la sociedad cristiana no les atraía sino más bien porque no querían resignarse, al abandonar su cultura y sus tradiciones, a convertirse en un grupo de impuros, de excluidos, de indeseables, «Le refus d'assimilation des Morisques: aspects politiquea et culturels d'après les sources inquisitoriales», Les Morisques et leur temps, Paris, CNRS, 1983, pp. 189-190.

24. Informe..., fol. 42. Según las Casas, al suprimir esas desigualdades fiscales "conocerán claramente que no pretenden sino la salud de sus almas y la honrra de sus personas, tratándolos como a todos los demás christianos antiquíssimos de España y de toda la Iglesia”, fol. 72.

25. Memorial al Rey Felipe III, fol. 155r.

26. Ibidem, fols. $155 \mathrm{r}-155 \mathrm{v}$. 


\section{RECHAZO DE LOS ESTATUTOS DE LIMPIEZA DE SANGRE}

Entre todas las discriminaciones, la aplicación de los estatutos de limpieza de sangre era la más exclusiva porque dificultaba el acceso de los cristianos nuevos (descendientes de judíos y de musulmanes) a ciertos oficios y puestos importantes en la estructura del Estado y de la Iglesia. Estos estatutos, que aparecen ya desde mediados del siglo XV, fueron adoptados a partir de 1556, año en que Felipe II aprobó el de la catedral de Toledo, por varias órdenes religiosas y militares, algunos colegios mayores, numerosas cofradías y gremios de artesanos y algunos capítulos catedralicios. La Compañía de Jesús acabó adoptándolos en 1593. A pesar de esta generalización, hay que subrayar que estos estatutos, que eran de derecho privado, no fueron adoptados por todos los cuerpos del Estado y de la Iglesia ${ }^{27}$. Ignacio de las Casas reclamaba su abrogación por considerarlos denigrantes y un obstáculo para la integración y conversión de los moriscos. En su «Información» dirigida a Clemente VIII en 1605, se indignaba contra la instituciones eclesiásticas que prohibían el acceso de los cristianos nuevos al sacerdocio o a cualquier otro cargo eclesiástico porque según él:

\footnotetext{
"No puede ser excluido de la honrra del sacerdocio el que tiene derecho para participar della y porque ésta fue instituida de Christo para todas las naciones del mundo nadie tiene auctoridad para excluir della alguna nación en siendo los della christianos y bastantemente cultivados con buena instrucción y doctrina, siendo hábiles y capazes y pasado ya el noviciado de christiandad, parece que tienen derecho para tener, sacerdotes y obispos de su nación" ${ }^{\prime 28}$.
}

Llegó incluso a pedirle al Papa que mandase "quemar todos los procesos de todas las inquisiciones y juntamente todos los sambenitos y que no se pudiessen llamar ni tener por christianos nuevos los que pasassen de cien arios después del baptismo de sus pasados"29.

27. Como lo apunta el dominico Fray Agustín Salucio en su Discurso sobre los estatutos de limpieza de sangre (1599): "Los que son tenidos por inhábiles para cualquiera cosa de las que piden información de limpieza (aunque sea para familiaturas de colegios, o para clerizones de tal iglesia, o para frailes legos de algún convento) no por eso son excluidos de otros grandes cargos, oficios y dignidades eclesiásticas o seglares; antes son admitidos a ser regidores y corregidores y a otros gobiernos y tribunales, y al sacerdocio y administración de los sacramentos, y a las religiones, y al púlpito, y a canonicatos, dignidades y obispados, y pueden ser condes y duques", en Antología de textos «La Monarquía católica» de Felipe II y los españoles, selección de textos y presentación por Rafael Carrasco y Alain Milhou, Paris, Éditions du Temps, 1998, p. 299.

28. «Información...», fol. 45.

29. Ibídem, fol. 53v. Aunque las Casas se oponía a los estatutos de limpieza de sangre, parecía sin embargo aceptarlos y hasta justificarlos para "con los que no an pasado el centenar después del baptismo de sus mayores", fol. 55. 
Entre los argumentos que avanzaban los partidarios de la no admisión de los moriscos al sacerdocio estaba el riesgo de apostasía. Las Casas lo rechazaba porque consideraba que "aunque los bautizan, no les enseñan la ley de Jesuchristo"30. En vez de discriminarlos, lo que había que hacer era favorecer los matrimonios mixtos e incitarles a vivir en los mismos barrios que los cristianos viejos, pero para ello había que quitarles antes "las notas de infamia assí ecelesiásticas como seculares" 31 .

\section{CALIDAD DEL CLERO ADSCRITO A LOS MORISCOS}

Los abusos cometidos por el clero (sobre todo el bajo clero) encargado de la evangelización de los moriscos eran notorios y tanto la Corona como la jerarquía eclesiástica tomaron medidas severas para poner fin a esta situación (junta de la Capilla Real de 1526, sínodo de Guadix de 1554, junta de Madrid de 1564 y de Valencia de 1565, etc.). La postura de las Casas era obviamente muy crítica. Según él, era capital que "los curas y rectores de toda esta gente y los que an de governar y regir estos collegios y casas y los que an de confessar y predicar sean hombres desinteresados, de buena vida y exemplo, castos y zelosos de la conversión destas almas" "32; era el modelo de sacerdote elaborado en Trento, el de un sacerdote virtuoso y ejemplar. Las Casas reconocía que sus condiciones de vida, especialmente en las zonas de moriscos, eran muy duras y proponía que se les aumentaran las rentas para poner fin a las exacciones. De paso, critica la actitud del alto clero que daba pruebas de poco celo y falta de caridad cristiana cuando se trataba de su dinero; y sin embargo, eran "tan ricos los obispados de España, [...], que bien les quedará a los perlados harto que dar a sus deudos y con qué acudir a otras necessidades no tan obligatorias ni tan forçosas" 33 .

Con una buena renta, los curas podrían, inspirándose en el modelo apostólico, enseñar y predicar en público, pero en las zonas de moriscos era difícil encontrar curas competentes y por ello se propuso que los religiosos participaran en la evangelización y conversión de la minoría. Su acción se desarrolló sobre todo en las misiones ya que éstas eran más acordes al espíritu de sus reglas y constituciones. Todo el mundo pensaba que los religiosos eran los más idóneos para realizar esta tarea.

30. Memorial al supremo Consejo de la Inquisición, fol. 176v.

31. Memorial al Rey Felipe III, fol. 157r.

32. Informe..., fol. 50r.

33. Ibidem, fol. $50 \mathrm{v}$. 
Varias campañas de evangelización fueron organizadas en el reino de Valencia entre 1527 y 1599, pero todas fracasaron. Con todo, las Casas seguía creyendo en la necesidad de reactivarlas:

"por quatro, cinco y más años [...] y que se les conceda un perdón general y jubileo pleníssimo que deve ser sin ser obligados a descubrir cómplices de sus errores y es muy puesto en razón que del día que se començaren a poner en execución los remedios, cese la Inquisición de castigarlos por quatro o cinco años en público aunque no cese de prenderlos y amonestarlos y aun penitenciarlos secretamente porque no se atrevan a desmandarse principalmente en Aragón y Valencia y, viéndose el fructo y provecho claro, entrará bien el quemar los procesos y quitar los sambenitos que dixe, lo qual se deve conceder primero a los que destas quatro suertes dellos más se aventajaren en su remedio para que visto y entendido este particular favor de los otros se animen y aspiren a alcançarle" ${ }^{34}$.

Para él se trataba de olvidar el pasado y de volver a empezar sobre unas nuevas bases; seguía teniendo esperanzas de ver a su pueblo volver al seno de la Iglesia.

En cuanto a la educación de la juventud, sus ideas encontraron un eco favorable en la junta de Valencia de noviembre de 1608-marzo de 1609 porque no diferían, en el fondo, de las que proponían las autoridades civiles y eclesiásticas.

\section{EDUCACIÓN DE LA JUVENTUD}

A partir de la junta de la Capilla Real de 1526, la Corona se dio cuenta de que las medidas coercitivas no eran suficientes y de que había que mejorar la educación de los moriscos para facilitar su comprensión de la doctrina cristiana. En dicha junta, se decidió la creación de varios colegios para los niños moriscos. En 1532 abría sus puertas en Granada el colegio de San Miguel; en principio estaba destinado a los morisquillos, pero ante la escasez de candidatos, acabó aceptando niños cristianoviejos. En 1558 no quedaba ni un solo morisco en la escuela. Las Casas atribuye este fracaso a las vejaciones y malos tratos que se les infligía a los niños:

"la causa de averse salido dellos tan tiernos en todo fue los malos tratamientos que los rectores, no cuerdos y discretos, les hizieron porque a los tan nuevos en la fe y costumbres nuestras quisieron apremiar luego a comer tocino y, haziéndoselos de malo y asqueroso como carne no usada, se lo refregavan por

34. Ibídem, fols. 72r-72v. La propuesta de las Casas de solicitar al Papa un edicto de gracia fue rechazada por la Junta de Valencia de 1608-1609, en Francisco de Borja de MEDINA, «La Compañía de Jesús...», p. 125. 
los hocicos y les hazían otras befas pesadas, diziéndoles palabras injuriosas y llamándolos perros moros. Oydo e a testigos dignos de fe que pasó esto assí y no es de maravillar que algunos de los primeros tan tiernos no saliessen como se deseava" ${ }^{\prime 35}$.

Su propuesta consistía en que, en cada pueblo, un cristiano viejo "de edad, virtud y exemplo" y una cristiana vieja se hiciesen cargo de la educación de los niños moriscos; proponía también que los padres fuesen obligados a mandar a sus hijos a la escuela "desde los siete años hasta que tengan catorze y las niñas doze y que no salgan dellas sin saber el testo de la doctrina christiana y sus preguntas y respuestas examinándolos con rigor" ${ }^{\prime 36}$. Los rectores y curas debían examinarlos todos los meses y recompensar a los buenos alumnos. Para evitar que este trabajo de aculturación fuese saboteado por los padres, las Casas insistía en que los jóvenes de entre 14 y 25 años fuesen apartados de la influencia de sus familias e instruidos en colegios y seminarios donde aprenderían, "los que fuesen para ello", humanidades, filosofia y teología. Pensaba en el éxito que habían tenido, según él, estos centros educativos en las Indias donde "estos collegios de los naturales son los que sustentan, fomentan y dilatan la ley evangélica y por ser tan clara y cierta esta verdad que se convierten los coraçones de los padres por sus hijos doctos y pios" ${ }^{\prime 37}$.

Otra estructura importante para nuestro jesuita eran las casas de catecúmenos; estas casas desempeñarían un doble papel de formación y de obra de caridad. En ellas se recogería a los niños huérfanos y también a los que las autoridades tuvieran que separar de sus familiares si éstos les inculcaban preceptos coránicos. La instrucción se haría según las capacidades de los alumnos, aplicando una pedagogía diferenciada, "los que fueren aptos para letras instruillos en lo necessario para esto hasta que tengan edad de entrar en los collegios, y los demás ponellos a officios y a las niñas a sus labores y con amas y a servir en varios conventos hasta la edad de eligir estado"38. Para financiar estos centros, las Casas proponía que se hiciera con el dinero que los moriscos entregaban a la Inquisición.

La originalidad de las propuestas de las Casas estriba en su obstinación en defender a toda costa la creación de colegios y seminarios en un momento en que, en España, prácticamente nadie veía la utilidad de hacerlo después de tantos intentos y fracasos; pero indudablemente, la propuesta que más detractores tenía era la de la utilización del árabe como lengua de evangelización. Fue rechazada de plano en la junta de Valencia de 1608 porque los

35. Informe..., fol. $45 \mathrm{v}$.

36. Ibídem, fol. 43v.

37. Ibídem, fol. $44 \mathrm{v}$.

38. Ibídem, fol. 49r-49v. 
prelados consideraban que "no sólo [no] sería útil para la instructión de la fe christiana, pero que causaría en los dichos moriscos nueva reputación y estimación de su secta y que los actuaría más en sus errores" 39 .

\section{EL ÁRABE COMO LENGUA DE EVANGELIZACIÓN}

Para nuestro jesuita, el aprendizaje del árabe era capital tanto a nivel religioso como a nivel político y estratégico.

En el memorial elevado al provincial de su orden en Castilla, Cristóbal de los Cobos (1607), las Casas no cesa de elogiar la lengua árabe; recuerda que era una de las lenguas más antiguas de la tierra, que se había difundido en África, Asia, Extremo Oriente y parte de Europa. La lengua árabe se había desarrollado en cierto modo gracias al avance del Islam y estaba tan extendida que "aunque quisiesen de propósito extinguirla y acabarla, no podría potencia humana en casi otro tanto tiempo [desde la Hégira] por tenella ya por natural y propia tantas y tan diversas naciones". Una de las razones por las que las autoridades españolas rechazaban la predicación en árabe era el temor a que sirviese de vector privilegiado de la cultura y de la religión musulmana; para calmar los espíritus, las Casas aseguraba que esa lengua no se había extendido gracias a los árabes y albCorán sino más bien por ser una lengua "elegante, copiosa, y tan affectuosa y que tiene tanta propiedad para dezir lo que quiere que excede a muchas otras y una vez sabida tira tras sí los coraçones; [...] en elegancia y copia no cede a la griega y latina ni en la diversidad de galana poesía en varios y diferentes géneros de metro". Esta lengua merecía tanto respeto como la hebrea, lengua de los patriarcas bíblicos, de los profetas, de Cristo, de sus apóstoles y discípulos, porque "a la arábiga se deve no pequeña honrra por averse dignado el Verbo Padre aparentar también con los árabes, trayendo parte de su descendencia Bellos por Ruth Moavita que era natural de Petra". Era también la lengua de los judíos que vivían en territorio musulmán y de los cristianos de Oriente que no por eso dejaban de ser buenos cristianos ${ }^{40}$. Querer prohibírsela a los moriscos valencianos era contrario al deber de la Iglesia porque eran cristianos y no se les podía dejar en un estado de ignorancia y de desconocimiento total de los principios cristianos:

"Dicho e que en dozientos años no se desarraigará la lengua destos naturales de Valencia si la quisiesen prohibir, que ni deven ni sería cordura. Siendo tan grande la multitud y siendo admitidos por hijos de la Iglesia, obligación precisa ay de dalles pasto saludable luego; éste no se les da con solos los curas o rectores que les ponen, que no se entienden entre sí. Esta obliga-

39. BORONAT, op. cit., p. 132.

40. Memorial a Cristóbal de los Cobos, fol.5. 224v-232r. 
ción de dalles pasto saludable y que le perciban es debaxo de peccado mortal a los que les toca darles esta doctrina, y claro se sabe quién[es] son a los que esto toca; no procurando dársela, no sólo no veo respuesta pero ni escusa aparente. Dezir que la procuran dar y no pueden más, veo que no es assí pues no toman los medios proporcionados que usó el espíritu sancto y los apóstoles" ${ }^{\text {"1 }}$.

Además, querer prohibir el uso de una lengua por decreto era una empresa destinada a fracasar porque:

"como la patria y la lengua se aman igualmente y más tiernamente la lengua por lo qual tiene nombre de materna, aunque la otra de patria, por el padre, por ser el amor más tierno, bebido a la leche de las madres y aunque la patria se dexa, la lengua jamás se olvida"42.

La realidad confirmaba este hermoso análisis de las Casas porque un siglo después de su conversión, los moriscos valencianos seguían ignorando la aljamía, y aunque algunos de ellos sabían algunos rudimentos de castellano o de valenciano, eran pocos y no entendían lo que se les predicaba.

Otro argumento en contra de la prohibición del árabe era el riesgo de provocar un levantamiento de los moriscos valencianos al igual que lo hicieran los granadinos:

“el prohibírsela sería odiosíssimo y dañosíssimo para su conversión y haría en ellos el efecto que hizo en los de Granada, que fue la cruel rebelión que costó tanta sangre de christianos, y los daños gravíssimos que del prohibírsela salieron son más claros y ciertos bien provados y vistos hasta oy que los provechos ymaginarios que se dizen"43.

Había que encontrar una solución para que los moriscos valencianos se convirtieran sin prohibirles su lengua materna, y esa solución pasaba por el aprendizaje del árabe por parte del personal encargado de la evangelización.

41. Ibídem, fol. 213v; en la Información al Papa, las Casas escribe: "En todo el reyno de Valencia (como tengo dicho) hablan todos los moriscos en arábigo sin aver quién les doctrine y enseñe como se deve, y es obligación precisa y forçosa enseñarles porque no es predicarles hablarles en lengua que no entienden; y el dezir que sí entienden es muy falso porque si en un pueblo de quinientas y mil almas entienden quatro nuestra lengua, es mucho y aun éstos no son capaces de percebir con razonamiento ordenado en cosas de la fe y esto es certíssimo; y querer quitarles y prohibirles la lengua y forçarlos a deprender la nuestra es imposible y aunque se les prohibiesse con pena de la vida y perdimiento de bienes, no se alcanzaría el intento en cien años v demás de que con irritarlos y impedirles la conversión no se cumplía con la obligación que ay (como no se a cumplido hasta aquí) de instruirlos en la fe que les hizimos recibir, que agrava mucho más esta obligación y se quedarán por nuestra culpa tantos millares de almas sin la doctrina necessaria para salvarse y se condenarán por la negligencia de los que les deven dar el remedio necessario", fols. $63 \mathrm{v}-64$.

42. Memorial e Cristóbal de los Cobos, fol. 233r.

43. Ibidem, fols. 200r-200v. 
Éste era el punto de vista de la Junta de Valencia de 1565, de la que se inspiró las Casas, que había propuesto que "ubiesse algún salario especialmente aplicado a quien enseñasse por agora arábigo a los que an de tratar de la conversión y reducción de todos los moriscos hasta que ellos aprendan el aljamia" ${ }^{44}$. Si los sacerdotes que se embarcaban para las Indias para evangelizar a los indios tenían que aprender "nuevas y más bárbaras y diffíciles lenguas que ésta", podían estudiar el árabe que, según él, podía aprenderse en tres años. La enseñanza se haría en los seminarios.

Había que incitar a las órdenes religiosas y a los párrocos a estudiarlo y a conocer el Islam; para ello, había que formar jóvenes teólogos y ofrecerles:

\begin{abstract}
"premios tales que animen y pongan espuelas y alas a muchos a deprenderla, tales serán aver en cada catredal [sic] dos raziones para esto, las quales se ayan de dar por oposición, que harto mejor empleadas estarían tales prebendas en theólogos doctos que no lo están oy en tantas personas que ni aún saben leer quanto menos otras ningunas letras [...]. También an de aver señalados beneficios curatos y simples para esto mesmo en todos los obispados y arçobispados y particularmente en aquellos que contienen mayor copia desta gente y con esto no hay que dudar sino que la conversión será la que se pretende en todas partes y se remediarán todas las cosas apunctadas $" 45$.
\end{abstract}

Pero las Casas quería ir aún más lejos, quería sobre todo que los jóvenes moriscos aprendiesen el árabe para ayudar en la conversión de su pueblo como auxiliares de la evangelización. Presintiendo quizá que su propuesta sería rechazada, se contentó con proponer la enseñanza del árabe sólo a los jóvenes moriscos destinados al sacerdocio. Estos jóvenes, tras seguir una formación teológica, ya no serían simples auxiliares sino que se convertirían en actores propios de la evangelización de su pueblo y serían de gran utilidad para convencer a los alfaquíes ${ }^{46}$. Su objetivo era formar una especie de unidad de elite compuesta por jóvenes seleccionados según sus capacidades e instruidos y formados en colegios y seminarios; gracias a ellos "se rendirán sin duda todos los demás y se liará una florida Iglesia dellos que son amigos de penitencia y devociones y inclinados a la piedad ${ }^{\prime 47}$ y se podría luchar más eficazmente contra los dogmatizadores.

44. «Información...», fol. 92v; Memorial a Felipe III, fol. 152v.

45. Memorial a Cristóbal de los Cobos, fols. 235r-235v.

46. «Información...», fol. 61r: "Será muy cierta la conversión desta miserable gente viendo que sus hijos que saben y entienden su secta mejor que sus grandes alfaquíes y les convencen en sus letras y en ella les dizen ser falsa y cierta y verdadera la ley evangélica".

47. Memorial al Rey Felipe III, fols. 160r-160v. 


\section{LUCHA CONTRA LOS DOGMATIZADORES O ALFAQUÍES}

Los alfaquíes fueron el blanco de todas las campañas de evangelización porque eran los verdaderos guardianes de los preceptos del Islam y animaban a sus correligionarios a enfrentarse directamente a los valores cristianos y a la cultura que vehiculaban. En vísperas de la expulsión, los ataques sucesivos de la Inquisición habían debilitado considerablemente su actividad, pero ésta persistía en Aragón y Valencia.

Al igual que las autoridades, las Casas preconizaba la expulsión de los dogmatizadores. Según él, si la minoría no se convertía era porque no veía a ningún alfaquí hacerlo sinceramente, "antes enseñaron lo contrario y lo dexaron escrito en varios libros que andan en manos de los que saben la lengua arábiga con gran cautela y secreto" 48 . Estos libros eran comentarios del Corán y obras de polémica anticristiana, escritos en árabe o en aljamiado. Según las Casas, había que refutar el contenido de estas obras, pero antes de hacerlo había que estudiarlas y analizarlas profundamente. Se quejaba nuestro jesuita de que las refutaciones existentes eran pésimas y ponían de manifiesto un gran desconocimiento del Islam:

\footnotetext{
"las confutaciones que andan en romance, en las quales topan tantas cosas que ni tienen ni dizen los moros ni sus libros y más quando les niegan que no tratan de las virtudes o que dan mucha libertad para los vicios y que su engañador no hizo milagros porque sus libros le atribuyen millares dellos, no los creen en nada, diziendo que como se engañan en aquellas cosas y contradizen con porfía lo que ni saben ni entienden, assí no dizen verdad en nada y este daño es gravíssimo para su conversión y por esto digo que importa sumamente hazer una exacta confutación por la qual los que les an de predicar o catechizar entiendan todo lo desta secta y lo que ellos piensan della y la sepan confutar y desengañallos poco a poco viendo ellos que lo saben y entienden muy bien todo y responden bien a sus dudas, que proponen muchas" 49 .
}

La causa de este desconocimiento era el desprecio que mostraba la Iglesia por el Islam, rechazando así todo acercamiento con los musulmanes, toda confrontación intelectual, racional ya que consideraba que "por ser secta tan material, carnal y bestial, [...] no avía que hazer caso del modo y término de su doctrina, ni cómo la enseña y prueva"50. Para rematar la acción contra los alfaquíes, las Casas insiste en la importancia de editar catecismos como el Catecismo para instrucción de los nuevamente convertidos de Moros de Ribera-Ayala (1599) que enseñaba la doctrina cristiana al mismo tiempo que se es-

48. «Información...», fol. 18v.

49. Ibidem, fol. 59v.

50. Ibidem, fol. 58v. 
forzaba en dar una imagen negativa del Islam, refutando los principios coránicos:

\begin{abstract}
"Importa grandemente el hazerles un exacto catechismo o confutación de su secta en la qual se les abran los ojos para ver las graves maldades que contiene y la perversa vida de su caudillo sin que puedan deprender cosas de sus errores, que es la falta que hasta oy an tenido los contra alcoranes que se an impreso y prohibido, con otra no menor que es imponer a la secta lo que no admitte y negarle muchas cosas de las que tiene. Con este catechismo se a de hazer otra exacta confutación, la qual an de tener y ver solos aquellos que les an de predicar y enseñar para que no ignoren nada de lo que conviene" ${ }^{, 51}$.
\end{abstract}

El estudio del Corán y de las obras de los alfaquíes podría ser muy útil para la Inquisición ya que dispondría así de personal cualificado para desbaratar todas las intrigas de los moriscos y también para traducir obras como los libros plúmbeos descubiertos en el Sacromonte de Granada entre 1588 y 1598.

Estos libros, compilación de leyendas e historias sagradas inspiradas de la cultura escrita y oral, eran una última tentativa de supervivencia del Islam en un contexto francamente desfavorable; si bien no se trataba, según Flagerty, de restaurarlo ${ }^{52}$. Las Casas, a petición del arzobispo de Granada don Pedro Vaca de Castro, analizó estos documentos y demostró que eran una superchería inventada por los moriscos porque muchos elementos hacían referencia a la cultura y a la religión musulmana. Sus conocimientos del árabe ${ }^{53}$ le permitieron traducir algunos de los documentos que nuestro autor no duda en catalogar como aljofores o alguacías, es decir:

"librillos de lo que sobre esto [pronósticos de cosas futuras] dixo su engañador, que ellos tienen por certíssimas e infalibles prophecías, y más las que tratan que an de enseñorearse destos reynos y oprimir a los christianos hasta hazellos de su secta y que ésta a de duraren España hasta la fin del mundo como se lo certifica su maldito caudillo y otras prophecías que tien[en] por tales de otros que ellos tuvieron por sanctos y andan entre ellos muchos traslados destos. Añaden a esta su esperanza la que saben casi todos que les dan

51. Memorial al Rey Felipe III, fols. 156r-156v.

52. HAGERTY, op. cit., pp. 49-50.

53. Según las Casas, Juan de Albotodo y Jerónimo de Mur tenían unos conocimientos limitados del árabe; hablaban el árabe dialectal pero no dominaban el árabe literario y tampoco sabían leerlo. Según Ana Labarta, que ha analizado algunas traducciones de Mur, éste "debía tener un buen conocimiento del árabe dialectal pero no estaba familiarizado con el árabe literario ni con la cultura islámica, lo cual le llevaba a cometer algunos errores de interpretación”, en «Notas sobre algunos traductores...», op. cit., p. 103. En cuanto a las Casas, éste reconocía también sus límites: "No a sido poco que aya llegado a entender lo que leo más que medianamente y de suerte que sé si es horror o no lo que leo y puedo predicar como lo e hecho en ella varias vetes en el reyno de Valencia y sé la gramática de modo que la puedo enseñar en breve", Memorial a Cristóbal de los Cobos, fol. 207. 
los libros del monte de Valparayso de Granada donde se dize por boca de la Virgen y testificado por Sanctiago que los árabes an de sugetar estos reynos y que son de las mejores naciones del mundo y que an de defender la verdad del Evangelio como diré en su lugar" ${ }^{\circ 4}$.

Otro aspecto muy importante señalado por Cabanelas y otros autores que han analizado estos documentos es el sincretismo religioso de doctrinas cristianas y musulmanas. Los autores de la superchería, probablemente los moriscos Miguel de Luna y Alonso del Castillo, procuraban reconciliar a las dos comunidades. Para ello intentaron encontrar un vínculo que fuera aceptable por los creyentes de las dos religiones, echando mano de las creencias musulmanas menos chocantes para los cristianos y viceversa.

Las concesiones eran mutuas: proposición de un Dios aceptable por todas las religiones monoteístas, aunque ese Dios se parecía asombrosamente a Alá; aceptación de la doctrina de la concepción virginal de Jesús; Jesús no era Hijo de Dios sino una manifestación de su Espíritu: "No ay otro Dios sino Dios, Jesús Espíritu de Dios" (si sustituimos Jesús por Mohammed y Espíritu por Profeta, tenemos la profesión de fe de los musulmanes).

El sincretismo era el fundamento de estos escritos pero, como lo subrayaba las Casas y más tarde, en el siglo XIX, el erudito Godoy Alcántara, tenemos también el sueño mesiánico de una posible restauración de un poder musulmán encarnado en la figura de un rey árabe que, como el imam Alí para los chiíes o Don Sebastián para los portugueses, reaparecería para demostrar a los cristianos que estaban equivocados y que no habían "seguido bien el Evangelio ni las [e]scrituras, [...], que nuestro Evangelio está depravado y no es el que enseñó Jesuchristo y tienen también por cierto que es verdad lo que tengo dicho que España a de ser otra vez suya y todos an de seguir la secta de su perverso Mahoma"s5.

Pero, ¿qué buscaban los autores de los libros plúmbeos? ¿Un Islam cristianizado o un cristianismo islamizado? Las dos opciones son plausibles. Por los árabes y su lengua, el cristianismo alcanzaría su apogeo; pero para conseguirlo tendría primero que desprenderse de todas sus falsificaciones y de las malas interpretaciones a la luz de la "verdadera doctrina", la del Corán.

El caso de los libros plúmbeos confirmó a las Casas en su opinión de que sólo una formación adecuada podía evitar que este tipo de incidentes se repitiera; en efecto, desconfiaba de los intérpretes porque no tenían una sólida formación teológica y religiosa y además, como se dio el caso en Granada, podían ser manipulados. Las Casas les acusaba de ser responsables de la agitación provocada por su mala interpretación del contenido de dichos libros:

54. Ibídem, fols. $170 \mathrm{v}-171 \mathrm{r}$.

55. Ibídem, fol. 187r. 
"Hasta oy se dize que muchas cosas de las halladas en aquella ciudad en arábigo no se an interpretado bien por no ser los intérpretes tan doctos aún en esta mesma lengua como los querría el señor arçobispo pues, ¡quánto más fuerça hará esto a buscarlos y procurarlos tales, siendo cosas de doctrina de la Iglesia y en que va tanto en que no se equivoquen, como se equivocarán, no siendo theólogos y no teniendo los requisitos para tal obra!"’56.

Estos intérpretes podían propagar herejías y ser responsables también de la mala conversión de los neófitos:

"Pues si para interpretar fielmente ay falta, ¿qué diré de la que ay para catechizar a los que se pretenden convertir, que es gravíssima? [...] ¿cómo puede estar seguro el maestro del neófito si entiende bien o mal los misterios de nuestra fe? De aquí nace lo que vemos y provamos con dolor que ay pocos convertidos desta secta de quien tengamos seguras esperanças que son de veras christianos, mucho digo en poco. ¿Cómo a de saber dezir el intérprete que sólo sabe esta lengua conforme a la secta de Mahoma y no es docto en nuestras letras, antes es necessario para entenderlo él otro intérprete que se lo declare quando a de dezir Trinidad, personas divinas, divina esencia, unión hipostática Dios y hombre, sacramentos, missa, comulgar y confesar, absolver y otros términos sin número que para los moros en su secta son tan inauditos como entre nosotros los de su Alcorán y ceremonias?" ${ }^{57}$.

Hasta ahora hemos visto el interés que podía tener el árabe como lengua de predicación en España, pero las Casas, como lo veremos a continuación, iba aún más lejos, ya que según él esta lengua podía contribuir, como lengua de predicación, a la expansión del cristianismo.

\section{MESIANISMO RELIGIOSO Y EXPANSIÓN IMPERIALISTA}

La Iglesia, gracias a unos predicadores instruidos, conocedores de la lengua, cultura y religión musulmanas, podría extender su influencia por todas las regiones del mundo que se encontraban bajo dominación musulmana ("se echaría a Mahoma destos reynos y aun de todo el Oriente con la predicación evangélica") y podría de este modo alcanzar las famosas cristiandades orientales cismáticas como eran las iglesias caldea, jacobita, copta y maronita que no eran consideradas, en la Edad Media, como heréticas pero que se diferenciaban de la Iglesia de Occidente por la extrañeza de sus ritos y la influencia de las culturas locales ${ }^{58}$.

56. Ibidem, fol. 222r.

57. Ibidem, fols. 214v-215r.

58. Cf. Alain MiLhou, «Découvertes et christianisation lointaine», en J.-M. MAYEUR et al. (dir.), Histoire du Christianisme, vol. 7, De la Réforme à la Réformation (1450-1530), París, 1994, parte III, cap. II, pp. 538-540. 
Las propuestas de las Casas estaban impregnadas del espíritu ignaciano de conquista espiritual de Dar-al-Islam, sueño que el fundador de la Compañía acarició hasta su muerte; la llave que proponía para abrir sus puertas era la lengua del Corán. San Ignacio animaba a aprenderla, pero en España los prejuicios contra todo lo musulmán tenían mucho arraigo. Pese a todo, las Casas seguía pensando que podía desempeñar un papel importante en la expansión imperialista de España. Si para Nebrija "siempre la lengua fue compañera del Imperio, y de tal manera lo siguió, que juntamente començaron, crecieron y florecieron, y después junta fue la caída de entrambos", para las Casas, el árabe podía acrecentar los dominios de la Corona, convirtiéndola así en la mayor potencia de la Historia:

“Todo el mundo sabe los presidios, plazas y ciudades que nuestro rey posee en el África y sus costas y los reynos que tiene en la costa occidental del Asia y en la India oriental donde esta lengua es común y ordinaria como natural casi de todas ellas pues ¿quién negará que para poseerlas seguramente, governarlas dichosamente y dilatar más su imperio y estender la fe en tan bárbaras naciones no tiene necessidad de seguros y fieles ministros que, sabiendo bien la lengua, no solamente hagan que obedezcan los vasallos con gusto y contento a su monarcha sino que los que son convertidos oygan de buena gana la doctrina evangélica y se muevan a seguirla?" 59 .

Expansión política y religiosa pero también realismo político e intereses económicos. A los que querían erradicar la lengua árabe de España les responde que "no consideran que tiene al África tan vezina que forçosamente a de comunicar y tratar con ella" ${ }^{60}$. Ignacio de las Casas soñaba de algún modo con una especie de aldea global cristiana dirigida por España y en la que "pudiessen pasear seguramente toda el África y el Asia y lo que de Europa posee esta lengua sin ser conocidos por estrangeros della" 61 .

En 1607, España no disponía de los medios ni de la capacidad para lanzarse en tal aventura ya que estaba ocupada en evangelizar a los indios de América y tenía los ojos puestos en los chinos y los japoneses.

Las ideas de las Casas que hemos intentado resumir aquí reflejan bien las inquietudes de la Iglesia, la cual desde el concilio de Trento se preocupaba más por la formación del pueblo cristiano y del personal encargado de guiarlo espiritualmente. Las Casas quería poner fin a los sufrimientos del pueblo morisco recordándoles a la Iglesia y a la Corona sus deberes.

59. Memorial a Cristóbal de los Cobos, fols. 215v-216r.

60. Ibidem, fol. 201v.

61. Ibidem, fols. $216 \mathrm{v}-217 \mathrm{r}$. 
Preconizaba una mejor formación del clero, un retorno al modelo apostólico y un mayor respeto de los cristianos nuevos. La barrera cultural que les incitaba a franquear era muy grande; había que interesarse por la cultura y la mentalidad de los que se quería convertir. Esta barrera era tanto más infranqueable cuanto que la cultura musulmana representaba a la cultura del Enemigo que hasta los espíritus abiertos rechazaban. Las Casas estaba convencido de que la causa primera del fracaso de la evangelización era el menosprecio y la humillación que padecían los moriscos así como el método empleado. La idea de nación árabe y cristiana inspirada en Talavera, pero limitada a la región de Valencia, la más islamizada, era uno de sus proyectos pero las medidas tomadas por la junta de 1608 mostraban bien que la Corona ya no estaba dispuesta a tergiversar; su respuesta fue la expulsión.

A la lectura de sus memoriales sentimos un desgarro, una lucha interna entre sus convicciones cristianas y sus orígenes porque sufría al ver a su pueblo despreciado por los cristianos viejos, por la Corona y por la Iglesia a la que pertenecía. En su «Información» preguntaba: “¿qué mayor infamia tienen éstos que los demás gentiles o Hijos de hereges o que los descendientes del judaísmo en estas partes?". Su atracción por la cultura musulmana podía parecer sospechosa, pero Ignacio de las Casas rechazaba el Islam y si se interesaba por la cultura musulmana era para convertir a los moriscos; sus proyectos de expansión del cristianismo en detrimento del Islam lo demuestran.

\section{RESUMEN}

Ignacio de las Casas presenta en su obra, redactada entre 1605 y 1607 ,

una alternativa a la política de evangelización y de asimilación de los moriscos. Tras analizar las posibles causas del fracaso de dicha política, propone una serie de soluciones para conseguir la conversión sincera de los moriscos a la fe cristiana. Inspirándose en todo lo que se había realizado en materia de evangelización en España desde la época de los primeros concilios de Toledo, las Casas insistirá sobre todo en la educación de los jóvenes, con el fin de utilizarlos como auxiliares de la evangelización, y en el aprendizaje de la lengua árabe, condición sino qua non para transmitir el mensaje cristiano a una población que no entendía la aljamía.

\section{ABSTRACT}

Ignacio de las Casas presents in his works, written between 1605 and 1607, an alternative to the policy of evangelización and assimilation of the Moriscos. After having analysed the possibe reasons of the failure of the 
above mentioned policy, he proposes various solutions in order to achieve a truth ful conversion of the Moriscos to the christian faith. Inspiring him self from everything that had been realized for evangelization in Spain since the time of the first councils of Toledo, las Casas insists mainly on the education of youngsters, with the aim to use them as auxiliaries of evangelization, and in the apprenticeship of the arabic, an essential step to transmit the christian message to a population that did not understand spanish. 